Microscopic Technique in Biology and Medicine By Prof. E. V. Cowdry. Pp. iv +206 . (Baltimore, Md. : Williams and Wilkins Co. ; London : Baillière, Tindall and Cox, 1943.) 22s.

$\mathrm{T}$ HIS is decidedly a book for the expert. It consists of an alphabetical arrangement of formulæ, references and short descriptive notes on microtechnical methods, and, as would be expected from its author, it is comprehensive, up to date and well documented. In fact, it is almost too comprehensive, for a number of subjects are included which are only on the fringe of the subject, while on the other hand some of the short articles on methods are so succinct that they suffer somewhat in intelligibility.

The alphabetical method has great advantages in some respects, where such varied material is collected together, but it is rather apt to lead the searcher on a steeplechase across the book when he wishes to get full information on a single subject. Thus "Fixatives", for example, involves sixty-four cross-references. An excellent feature, however, is the printing of all cross references in heavy type, which makes it easy to follow them up.

The first impression on looking into the book is that everything possible is here, but that is going a little too far. The temptation in reviewing such a cyclopredic work is to sigh over the absence of some of the reviewer's own pets, instead of praising the author's actual achievement, but even so, and allowing for the explicit exclusion of plant techniques, it is a pity that there is no mention of Newton's invaluable gentian-iodine technique for chromosomes, and it is surprising that Leishman's blood stain is absent, though it is still widely used.

It would be ungenerous to carp at occasional misspellings and similar trifles, but the reviewer cannot but protest, though humbly, against one more usurpation of the term "Biology" by animal science, in the title of the book. What is wrong with plain "Zoology", when plants are excluded?

Every practising microtechnician will find that this work is one that he will want to keep handy in his work-room. It will be to him of constant and, we hope, of permanent value, not least for the rich store of references it contains.

$$
\text { R. C. McLean. }
$$

\section{The Diagnosis of Mineral Deficiencies in Plants by} Visual Symptoms

A Colour Atlas and Guide. By Dr. T. Wallace. Pp. vi $+116+114$ plates. (London : H.M. Stationery Office, 1943.) 10s. net.

$\mathrm{D}$ URING recent years one of the most important advances in relation to the growth of field crops has been the recognition of the important part played by minute traces of elements other than those usually applied as fertilizers. Deficiency of any essential nutrient is reflected in some way in the growth and colour of the plant, and Dr. Wallace has performed a useful service to all agriculturists by collecting and describing a series of one hundred and fourteen colour photographs of various crops showing mineral deficiencies. The aim is to provide a means whereby deficiencies can be recognized and rectified at an early stage of growth, so enabling a full crop to be obtained. A scheme is indicated whereby land of unknown cropping potentialities can be tested by growing a series of indicator plants with various fertilizer treatments, the indicators being selected for their special susceptibility to a wide range of de- ficiencies. Where a visual diagnosis is doubtful the matter can often be settled by simple methods of spraying, responses to such treatments usually appearing within ten or fourteen days. Special attention has been given to the most urgent questions of war-time production, deficiencies such as copper, zinc and sulphur, which are not known as practical problems in Great Britain, being omitted. The illustrations, with the accompanying diagnostic key, provide a fund of most useful information.

\section{Encyclopedia of Substitutes and Synthetics}

Edited by Morris D. Schoengold. Pp. 382. (New York : Philosophical Library, Inc., 1943.) 10 dollars.

THIS "Encyclopedia" is very lavish of space; I not only is it set out with a wealth of leads" that reminds me of much pre-war practice, but also the diction is in many places unnecessarily verbose. For example, instead of stating that atabrine is slightly soluble in water, there is a sub-heading "Solubility", and well below the words "Soluble in water only to a slight extent". The very wide spacing and the reiterated sub-headings may make for easy finding, but a more compact form of presentation, with some tables of physical constants, etc., would have reduced the size, weight and price of the volume, or allowed of the inclusion of many more uses.

A few curious statements have been noted: in referring to the production of ammonium sulphate by the destructive distillation of coal, it is asserted that "If the ammoniacal vapors are conducted into sulfuric acid and then crystallized and dried, ammonium sulphate of commerce is obtained". Calcium phosphate and calcium sulphate are both described as white powders which are found free in Nature. Despite such blemishes the book will be found useful by all who need up-to date 'potted' information on substitute and synthetic materials.

E. H. T.

\section{Dictionary of Science and Technology in English-} French-German-Spanish

By Dr. Maxim Newmark. Pp. xvi+386. (New York : Philosophical Library, Inc., 1943.) 6 dollars.

$T$ HIS dictionary contains ten thousand English terms that are frequently used in the physical sciences and their applied fields, together with separate indexes in French, German and Spanish, conversion tables and technical abbreviations. The total number of entries, including cross-references, is about fifty thousand. The English part is divided into alphabetical sections (A, B, C, etc.); each word is followed by its equivalent in French, German and Spanish, always in that order, and a number. Parts containing the foreign words follow, each word bearing a letter and a number referring to the English part. An example will make this clear :

Border, chaudière $f$.; Dampfkessel m. ; caldera f. . . [354].

Chaudière, B354;

and similarly for the German and Spanish words.

This arrangement saves an extraordinary amount of space, in comparison with the arrangement usual in polyglot dictionaries. The pure sciences included are chemistry, physics and some mathematics. Of the applied sciences engineering, in all its branches, is particularly well treated, but meteorology, navigation, and photography also receive attention.

The book is a credit to the institution where it was conceived-the Brooklyn Technical High School. E. H. T. 